\title{
Exploiting Heterosis in Pearl Millet for Population Breeding in Arid Environments
}

\author{
T. Presterl* and E. Weltzien
}

\begin{abstract}
In the desert region of Rajasthan, India, farmers mainly grow pearl millet [Pennisetum glaucum (L.) R. Br.] landraces. The adoption of modern cultivars is generally low because of their poor adaptation to extreme drought stress. The objective of this study was to evaluate the performance of six elite breeding populations and three landraces and to determine the heterotic pattern among the $\mathbf{3 6}$ diallel crosses of those populations. Field experiments were conducted in eight environments in India. Mean grain yields (GYs) in the three environments with favorable growing conditions were double to threefold those in the three arid environments. The elite populations generally showed higher GY than the landraces; stover yield (SY) was similar in both population types. The landraces flowered earlier, had a higher tillering potential, and smaller seeds. Mean level of midparent heterosis was generally low, ranging from $0.85 \%$ for time to flowering (TF) to $6.57 \%$ for SY. For GY, expression of heterosis for individual population crosses was between -14 and $+30 \%$ under drought stress, and between -9 and $+17 \%$ in the favorable environments. For SY, mean heterosis was always positive and higher than for GY. The elite $\times$ landrace population crosses with high mean GY and high levels of heterosis under drought stress could be beneficial to widen the germplasm base and to combine the high yield potential of elite materials with the good adaptation of the landraces.
\end{abstract}

$\mathrm{P}$ EARL MILlET is a staple food crop in the semiarid and arid areas of Africa and Asia. In India, modern cultivars, both hybrids and open-pollinated cultivars, have been widely adopted throughout the pearl-milletgrowing regions (Kelley et al., 1996) because of their high yield potential and resistance to diseases. Adoption rates are lowest in the drier regions of the country and especially in desert areas of western Rajasthan, where pearl millet is the principal grain crop for human consumption and an indispensable fodder plant for animal production. Traditional landraces with lower yield potential but with adaptation to the environmental stresses in these areas are most commonly grown. Farm household surveys in Rajasthan showed that improved cultivars were not adopted by farmers because of insufficient grain and straw yield under conditions of drought stress (Kelley et al., 1996) and because of poor food quality (Christinck, 2002). Therefore, one important task is to develop improved breeding materials specifically suited to these harsh environments. The basic material for population or hybrid breeding could be derived from landraces with adaptation to stress environments or

T. Presterl, Inst. of Plant Breeding, Seed Science, and Population Genetics, Univ. of Hohenheim, D-70593 Stuttgart, Germany; and E. Weltzien, International Crops Research Institute for the Semi-Arid Tropics (ICRISAT), B.P. 320, Bamako, Mali. Received 25 Mar. 2002. *Corresponding author (presterl@uni-hohenheim.de).

Published in Crop Sci. 43:767-776 (2003). from improved elite breeding populations with high yield potential and high levels of disease resistance.

In the dry areas of western Rajasthan, farmers use diverse strategies to improve their own landraces (Weltzien, 2000; Christinck, 2002). These strategies include the introgression of modern cultivars with high yield potential into well-adapted landraces. Information about combining ability and heterotic pattern of the current breeding materials can be used, on the one hand, to optimize farmer breeding; it could, on the other hand, help conventional on-station breeding programs to create new source populations for hybrid and population breeding with increased genetic variability and to combine adaptation with yield potential.

The objectives of this study were to evaluate the performance of six elite breeding populations and three landraces in contrasting environments and to determine the heterotic pattern among diallel crosses of those populations. Through this analysis, the most promising ways to use these materials in population improvement programs for the arid zone environments of Rajasthan are explored.

\section{MATERIALS AND METHODS}

\section{Genetic Materials}

The genetic materials used for this study were six pearl millet populations developed by the International Crops Research Institute for the Semi-Arid Tropics (ICRISAT) in India and three landraces from the region. The ICRISAT populations were early maturing composites with varying proportions of Indian and African genetic materials, developed specifically for arid environments. The three landrace populations from Rajasthan and Pakistan were expected to have superior adaptation to extreme drought conditions.

\section{Elite Populations}

EC-C6: Early Composite Cycle 6, based largely on Indian breeding materials, mostly originating from the Gujarat pearl millet-breeding program. New early-maturing breeding lines from other ICRISAT composites were introgressed in every selection cycle.

EC II: Early Composite II, developed by random-mating early-flowering progenies from ICRISAT's medium-maturity breeding populations, which draw on African, including some Iniadi landraces, and Indian germplasm. It was originally called the Early Gene Pool.

EC 87: Early Composite 87, developed by random mating EC II, with two cultivars from the Bold Seeded Early Composite (BSEC) and one cultivar from EC-C6. The BSEC is based mainly on landrace germplasm from Togo and Ghana.

Abbreviations: AMMI, additive main effects and multiplicative interaction; GY, grain yield; ICRISAT, International Crops Research Institute for the Semi-Arid Tropics; IPC, ICRISAT pollinator collection; PP, panicles per plant; SY, dry stover yield; TF, time to flowering; $\mathrm{TG}$, thousand-grain weight. 
EC 89: Early Composite 89, a population cross of EC-C6 with BSEC.

\section{Elite High-Tillering Populations}

HiTiP 88 and HiTiP 89: High Tillering Population 88 and 89 , respectively. The parental materials of these populations were mainly high-tillering pollinator lines from the ICRISAT pollinator collection (IPC). The IPC parents of HiTiP 88 differ from those of HiTiP 89.

\section{Landrace Populations}

WRajPop C2: Western Rajasthan Population based on 13 landrace accessions from northwestern India. This population has been improved by two cycles of $S_{1}$-progeny selection for downy mildew resistance (Weltzien R. and King, 1995).

PakLR 74: A landrace from Pakistan (ICRISAT genebank IP 18065), collected in a region where cultivation follows flash floods (Weltzien and Bhatti, 1991).

LRE 128: A landrace from western Rajasthan (ICRISAT genebank IP 3425).

A detailed description of the materials, except the landraces PakLR 74 and LRE 128, is given by Yadav and Weltzien (1998). To analyze the heterotic pattern, 36 crosses among the nine parental populations were produced according to a diallel mating scheme. A minimum of 50 panicles was pollinated with pollen bulked from a minimum of 25 panicles every day for a minimum of $14 \mathrm{~d}$. Crossing continued during the core flowering period of each population and a minimum of 200 plants were pollinated for each cross. Reciprocal crosses were made, and seed was bulked to exclude maternal effects. Crossing was done during the dry post-rainy season, when good seed quality is assured.

\section{Field Experiments}

The nine populations, along with their 36 crosses, were evaluated in eight environments (Table 1) during the rainy seasons (July to September) of 1991, 1992, and 1993. The test locations were subdivided into three groups according to their latitude, mean GY of the trials, and environmental conditions (rainfall, fertilizer input, and soil type). These groups were: (i) the arid zone environments of northwestern India at the Rajasthan Agricultural University research station in Fatehpur-Shekhawati and at the Central Arid Zone Research Insti- tute in Jodhpur; (ii) the more favorable production environments of northwestern India at the Haryana Agricultural University Farm at Hisar, Haryana, and (iii) the test environments at ICRISAT at Patancheru near Hyderabad in Andhra Pradesh.

The trials in Fatehpur and Jodhpur were completely rainfed, under conditions of high radiation and midday temperatures $>$ $35^{\circ} \mathrm{C}$. Radiation and temperature levels at Hisar were similar to those of Jodhpur and Fatehpur but less arid with higher soil water-holding capacity and higher relative humidity because of widespread irrigation in the surrounding area. Thus, conditions were much less arid. The trials in Patancheru were grown under conditions of high fertility and sufficient water supply.

Field design for the experiments at Rajasthan, Hisar 1991, and Patancheru 1991 was an 8 by 8 lattice with four replications including populations, population crosses, and check cultivars. The experiments at Hisar (1992) and Patancheru (1992 and 1993) were laid out as an 11 by 11 lattice with four replications.

The experiments in all environments were machine-planted in four-row plots of 4-m length with an interrow distance between $45 \mathrm{~cm}$ (Hisar 1992) and $75 \mathrm{~cm}$ (all others). Experiments were overplanted and thinned to a final plant density between four (Rajasthan) and nine plants per square meter (Patancheru and Hisar). Plant densities were adjusted according to the water availability of the different environments. Before planting, 10 to $18 \mathrm{~kg} \mathrm{ha}^{-1} \mathrm{~N}$ and 20 to $40 \mathrm{~kg} \mathrm{ha}^{-1} \mathrm{P}$ $\left(\mathrm{P}_{2} \mathrm{O}_{5}\right)$ fertilizers as diammonium phosphate were banded below the rows, following the standard cultural practices of the respective experimental station. An additional application of 12 to $46 \mathrm{~kg} \mathrm{~N} \mathrm{ha}{ }^{-1}$ in the form of urea was side-dressed $\approx 20 \mathrm{~d}$ after emergence. The plots were kept free from weeds manually and by cultivation.

The following traits were recorded or calculated for each plot: Time to flowering, recorded as the number of days from planting date until $50 \%$ of the plants of each plot had stigma emergence in main shoot panicles, number of panicles per plot recorded at maturity, and panicles per plant (PP) calculated for each plot. At maturity, all panicles in the central $3 \mathrm{~m}$ of the four rows were harvested by hand. The panicles were dried, weighed, threshed, and the grain weighed to determine GY $\left(\mathrm{g} \mathrm{m}^{-2}\right)$. The stover was cut at ground level and fresh weight of the stover was recorded. A subsample was taken, weighed, dried, and reweighed to determine moisture percentage. Dry

Table 1. Seasonal rainfall, coefficient of variation for grain yield (GY), means for GY, stover yield (SY), time to flowering (TF), number of panicles per plant (PP), and thousand-grain weight (TG), and midparent heterosis for traits in individual test environments averaged across the nine parent populations and their 36 crosses.

\begin{tabular}{|c|c|c|c|c|c|c|c|c|c|c|c|c|}
\hline \multirow[b]{2}{*}{ Environment } & \multirow{2}{*}{$\begin{array}{l}\text { Seasonal } \\
\text { rainfall } \dagger\end{array}$} & \multirow{2}{*}{$\begin{array}{l}\text { CV } \\
\text { GY }\end{array}$} & \multicolumn{5}{|c|}{ Mean } & \multicolumn{5}{|c|}{ Midparent heterosis } \\
\hline & & & GY & SY & TF & $\mathbf{P P}$ & TG & GY & SY & TF & $\mathbf{P P}$ & TG \\
\hline & mm & $\%$ & $-\mathrm{g}$ & 2 & d & No. & $\mathbf{g}$ & 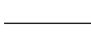 & 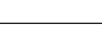 & $-\%$ & & 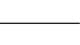 \\
\hline \multicolumn{13}{|l|}{ Rajasthan } \\
\hline Fatehpur, 1991 & 282 & 28.4 & 141 & 367 & 49.3 & 3.68 & 7.15 & 9.08 & 2.17 & -0.37 & -5.10 & 5.06 \\
\hline Jodhpur, 1991 & 182 & 17.7 & 106 & 221 & 53.0 & 2.21 & 7.76 & 3.15* & 2.04 & 0.77 & $-5.89 *$ & 5.40 ** \\
\hline Jodhpur, 1992 & 377 & 24.2 & 118 & 179 & 47.1 & 2.33 & 9.02 & 4.22 & $12.13^{*}$ & $1.55^{*}$ & 4.91 & $4.46^{* *}$ \\
\hline \multicolumn{13}{|l|}{ Hisar } \\
\hline 1991 & 193 & 13.0 & 221 & 500 & 48.9 & 2.94 & 9.99 & 2.28 & 7.63* & 1.03 & 2.54 & $6.54 * *$ \\
\hline 1992 & n.a.t & 22.1 & 168 & 398 & 48.7 & 2.12 & n.a. & -4.83 & 4.30 & 0.94 & 0.46 & n.a. \\
\hline \multicolumn{13}{|l|}{ Patancheru } \\
\hline 1991 & 419 & 13.9 & 261 & 383 & 41.2 & 3.98 & 10.20 & 2.97 & 3.56 & 0.57 & 2.48 & 1.86 \\
\hline 1992 & 469 & 7.2 & 280 & 379 & 42.7 & 3.98 & 10.19 & 0.94 & $12.30 * *$ & 0.46 & 2.50 & $5.66 *$ \\
\hline 1993 & 481 & 10.4 & 324 & 362 & 44.4 & 3.84 & 9.73 & 1.43 & $8.45^{*}$ & $1.88 * *$ & $10.67 * *$ & 1.54 \\
\hline Overall mean & 343 & - & 202 & 349 & 46.9 & 3.13 & 8.01 & 2.41 & $6.57 * *$ & $0.85^{*}$ & 1.57 & $4.35^{*:}$ \\
\hline
\end{tabular}

* Significance of average heterosis in the Gardner and Eberhart analysis II at the 0.05 probability level.

** Significance of average heterosis in the Gardner and Eberhart analysis II at the 0.01 probability level.

$\dagger$ From planting to harvest.

$\ddagger$ n.a., not assessed. 
stover yield $\left(\mathrm{g} \mathrm{m}^{-2}\right)$ was calculated from fresh weight and moisture percentage. Thousand-grain weight (TG, g) was determined from the mean weight of two 100 -seed samples.

\section{Statistical Analyses}

Lattice analyses of variance were performed for each location. Lattice-adjusted means and effective error mean squares were used in the combined analyses across environments (Cochran and Cox, 1957). Year and location combinations were considered as random and populations and their crosses were considered as fixed effects.

Gardner and Eberhart's (1966) Analysis II was used to estimate genetic effects and their variances by fitting the lattice-adjusted means of the nine parental populations and their 36 crosses to the following linear model:

$$
y_{\mathrm{ij}}=\mu+1 / 2\left(p_{\mathrm{i}}+p_{\mathrm{j}}\right)+\lambda h+\lambda\left(h_{\mathrm{i}}+h_{\mathrm{j}}+s_{\mathrm{ij}}\right),
$$

where $y_{\mathrm{ij}}$ is the population or population cross mean, $\mu$ is the mean of all populations, $p_{\mathrm{i}}$ and $p_{\mathrm{j}}$ are the population effects calculated from the difference between the mean of a parent and the mean of all parents, $h$ is the average heterosis, which is the difference between the mean of all crosses and the mean of all parents, $h_{\mathrm{i}}$ and $h_{\mathrm{j}}$ is the contribution of each population to the expression of heterosis measured as deviation from average heterosis, $s_{\mathrm{ij}}$ is the specific heterosis that occurs when Population $\mathrm{i}$ is mated to Population $\mathrm{j}, \lambda=0$ when $\mathrm{i}=\mathrm{j}$, and $\lambda=1$ when $\mathrm{i} \neq \mathrm{j}$.

As described by Gardner and Eberhart (1966), the sums of squares, which contribute to each parameter, were estimated by fitting successively more complex models. Midparent heterosis was calculated as the difference between the performance of the cross and the mean of the parents, relative to the mean performance of the parents. Significance of heterosis for each cross was tested with a $t$ test, comparing the midparent and the population cross mean.

Entry $\times$ environment interaction effects for GY were analyzed using the AMMI (additive main effects and multiplicative interaction) model (Crossa et al., 1990). This method estimates interaction effects in standard ANOVA with entries (populations and crosses) and environments as main factors, and subsequently fits the interaction effects in a principal component analysis.

Analyses of variance were computed with the GENSTAT software package (1993, Version 5, Release 3, VSN International Ltd., Hemel Hempstead, U.K.). The AMMI analysis was calculated using the PROC IML algorithm of the software package SAS (Release 6.03, SAS Institute, Cary, NC). The SAS code for calculating the AMMI analysis was kindly provided by Dr. B. Schill and is described in Link et al. (1996).

\section{RESULTS Environmental Means}

Rainfall during the growing seasons ranged from $182 \mathrm{~mm}$ at Jodhpur (1991) to $481 \mathrm{~mm}$ at Patancheru (1993) (Table 1). The Rajasthan environments received generally lower amounts of rainfall than in the Patancheru environment. Drought stress in the Rasjasthan environments occurred in all three years before flowering. Jodhpur was exceptionally dry in 1991, with a rain-free period of $40 \mathrm{~d}$ after emergence. No terminal stress was observed in the field experiments. Coefficients of variation for GY (Table 1) were on average higher in the drought-stressed environments of Rajasthan compared with the more favorable environments of Patancheru.

Mean GYs in Patancheru were double to threefold those in the Rajasthan environments and 50\% higher than mean GYs in Hisar. These yield levels correspond to contrasting growing conditions during the experimental period and confirm the subdivision of the test environments into the three groups. Stover yield was highest at Hisar, but differences between location means were less distinct than those for GY. At Patancheru, flowering was on average $7 \mathrm{~d}$ earlier, plants had $43 \%$ more PP, and TG was $26 \%$ higher than in the Rajasthan environments. The difference in flowering was in part caused by the longer daylengths in Rajasthan, and in part by the effects of the severe early droughts, particularly in 1991, which caused delayed flowering of all genotypes.

\section{Performance of Parents and Population Crosses}

The GY of the elite populations was distinctly higher compared with the landraces (Table 2) and corresponded to their high population effects in the Gardner and Eberhart Analysis II (data not shown). Population EC II had the highest GY across all eight environments as well as across Rajasthan environments, while EC 87 was the highest-yielding population across the three Patancheru environments (Table 2, Table 3). The two elite high-tillering populations showed an intermediate GY performance, which was most apparent at Patancheru. Stover yield of elite materials was of the same magnitude as SY of landraces in Rajasthan and Patancheru. The three landraces flowered on average $4 \mathrm{~d}$ earlier and tillered more, with double the number of PP compared with the elite parents. Reduction of number of panicles under stress conditions was more pronounced with the elite populations than with the landraces. Mean thousand-grain weights of the landraces and the elite high-tillering populations were lower, 7.4 and $8.0 \mathrm{~g}$, respectively, compared with the elite parents $(10.5 \mathrm{~g})$.

Among the 10 highest-yielding crosses in Rajasthan were two elite $\times$ elite crosses, five elite $\times$ elite high-tillering crosses, and three elite $\times$ landrace crosses (Table 4, Fig. 1). Four of those 10 crosses expressed significantly positive midparent heterosis for GY. In Patancheru,

Table 2. Performance of the nine parent populations for grain yield (GY), stover yield (SY), time to flowering (TF), number of panicles per plant (PP) across eight environments, and for thousand-grain weight (TG) across seven environments.

\begin{tabular}{|c|c|c|c|c|c|}
\hline Parent & GY & SY & TF & PP & TG \\
\hline & \multicolumn{2}{|c|}{$-\mathbf{g ~ m}^{-2}-$} & d & No. & $\mathbf{g}$ \\
\hline \multicolumn{6}{|l|}{ Elite } \\
\hline EC-C6 & 231 & 339 & 47.7 & 2.46 & 9.14 \\
\hline EC II & 243 & 348 & 47.5 & 2.02 & 10.88 \\
\hline EC 87 & 235 & 345 & 48.7 & 2.14 & 10.82 \\
\hline EC 89 & 222 & 301 & 46.6 & 1.99 & 10.95 \\
\hline \multicolumn{6}{|c|}{ Elite high-tillering } \\
\hline HiTiP 88 & 215 & 354 & 49.5 & 3.11 & 8.30 \\
\hline HiTiP 89 & 213 & 364 & 49.0 & 3.17 & 7.60 \\
\hline \multicolumn{6}{|l|}{ Landrace } \\
\hline WRajPop C2 & 179 & 363 & 45.5 & 3.80 & 7.97 \\
\hline PakLR 74 & 129 & 250 & 41.5 & 4.48 & 6.48 \\
\hline LRE 128 & 132 & 336 & 43.7 & 4.81 & $\mathbf{7 . 7 5}$ \\
\hline LSD0.05 & 35 & 44 & 1.5 & 0.51 & 0.75 \\
\hline
\end{tabular}


Table 3. Performance of the nine parent populations for grain yield (GY), stover yield (SY), time to flowering (TF), number of panicles per plant (PP), and thousand-grain weight (TG) across three Rajasthan (RAS) and three Patancheru (PAT) environments.

\begin{tabular}{|c|c|c|c|c|c|c|c|c|c|c|}
\hline \multirow[b]{2}{*}{ Parent } & \multicolumn{2}{|c|}{ GY } & \multicolumn{2}{|c|}{ SY } & \multicolumn{2}{|c|}{ TF } & \multicolumn{2}{|c|}{ PP } & \multicolumn{2}{|c|}{ TG } \\
\hline & RAS & PAT & RAS & PAT & RAS & PAT & RAS & PAT & RAS & PAT \\
\hline & 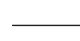 & 工 & $\ldots$ & - & ${ }_{-}$ & - & 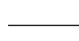 & 工 & 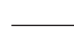 & 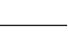 \\
\hline \multicolumn{11}{|l|}{ Elite } \\
\hline EC-C6 & 129 & 333 & 256 & 350 & 51.4 & 43.1 & 1.95 & 3.22 & 7.61 & 10.41 \\
\hline EC II & 139 & 350 & 270 & 376 & $\mathbf{5 0 . 7}$ & 43.7 & 1.62 & 2.65 & 9.31 & 12.11 \\
\hline EC 87 & 118 & 363 & 238 & 403 & 52.0 & 44.4 & 1.80 & 2.85 & 8.83 & 12.57 \\
\hline EC 89 & 137 & 314 & 221 & 318 & 50.0 & 42.3 & 1.80 & 2.48 & 9.43 & 12.14 \\
\hline \multicolumn{11}{|c|}{ Elite high-tillering } \\
\hline HiTiP 88 & 99 & 329 & 228 & 407 & 52.3 & 45.9 & 2.52 & 4.16 & 6.94 & 9.28 \\
\hline HiTiP 89 & 122 & 308 & 285 & 395 & 52.4 & 44.9 & 2.82 & 4.00 & 6.62 & 8.49 \\
\hline \multicolumn{11}{|l|}{ Landrace } \\
\hline WRajPop C2 & 113 & 243 & 267 & 374 & 48.0 & 42.1 & 3.67 & 4.46 & 7.42 & 8.33 \\
\hline PakLR 74 & 94 & 162 & 191 & 264 & 43.3 & 37.7 & 4.54 & 4.74 & 5.97 & 7.02 \\
\hline LRE 128 & 103 & 162 & 272 & 303 & 46.2 & 38.3 & 4.77 & 5.50 & 7.21 & 8.10 \\
\hline LSD0.05 & 37 & 28 & 63 & 82 & 2.1 & 2.6 & 1.14 & 0.63 & 1.26 & 0.51 \\
\hline
\end{tabular}

only elite $\times$ elite and elite $\times$ elite high-tillering crosses were among the 10 highest-yielding crosses and the 36 crosses could be clearly separated into low-yielding crosses with a landrace parent and into high yielding elite $\times$ elite or elite $\times$ elite high-tillering crosses (Fig. 1 ).

Across all environments, variation among entries and environment $x$ entry interaction variance were highly significant for all traits (Table 5). When the analyses of variance of grain and SY were computed separately for each of the three groups of environments, variation among entries was also significant or highly significant, except for SY at the two Hisar environments (Table 6). In this analysis, environment $X$ entry interaction variance for GY was only significant across the three Patancheru environments. For SY, interaction variance was highly significant at Patancheru and at the Rajasthan environments.

Dissection of the environment $\times$ entry effects matrix for GY following the AMMI model showed that Principal Component 1 explained $71 \%$ of the environment $\times$ entry interaction variance (data not shown). Principal Component 1 clearly separated the environments with favorable growing conditions (Patancheru) from the dry environments of Rajasthan (Fig. 2). The elite and the elite high-tillering parents, the elite $\times$ elite, and the elite $\times$ elite high-tillering population crosses tended to interact positively with the Patancheru environments. In contrast, the landrace parents PakLR 74 and LRE 128 and the landrace $\times$ landrace population crosses showed positive interactions with the stress environments of Rajasthan. The improved landrace population WRajPop $\mathrm{C} 2$, the elite $\times$ landrace, and the elite hightillering $\times$ landrace population crosses grouped together with the Hisar environments and their interaction effects were intermediate between the pure landrace and the pure elite groups.

\section{Heterosis}

The overall differences between parents and population crosses ranged from $0.85 \%$ for TF to $6.57 \%$ for SY and were significant only for some of the traits (Table 1). The largest average heterosis values for GY were observed in the three Rajasthan environments, indicating that GY under drought stress was reduced relatively less in population crosses than in parent populations. Only in Jodhpur 1991, the driest year, were significant differences obtained, however. Midparent heterosis for GY of individual population crosses ranged between $-14 \%$ and $+30 \%$ when averaged across the three Rajasthan locations and the mean heterosis values across the Patancheru environments varied between -9 and $+17 \%$ (Fig. 1).

Table 4. Means and midparent heterosis (MPH) for grain yield (GY) and stover yield (SY) of the 10 highest grain-yielding population crosses expressed as percentage, and ranks for SY, panicles per plant (PP), time to flowering (TF), and thousand grain weight (TG), at the three Rajasthan environments.

\begin{tabular}{|c|c|c|c|c|c|c|c|c|}
\hline \multirow[b]{2}{*}{ Population cross } & \multicolumn{2}{|c|}{ Mean } & \multicolumn{2}{|c|}{ МРН } & \multicolumn{4}{|c|}{ Ranks $\dagger$} \\
\hline & GY & SY & GY & SY & SY & TF & $\mathbf{P P}$ & TG \\
\hline & \multicolumn{2}{|c|}{$\longrightarrow \mathbf{g ~ m}^{-2}$} & 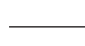 & - & & & & \\
\hline EC $89 \times$ WRajPop C2 & 155 & 305 & $25.1^{*}$ & $27.5^{*}$ & 2 & 25 & 22 & 4 \\
\hline EC $89 \times$ HiTiP 89 & 153 & 271 & $29.6^{* * *}$ & 20.5 & 11 & 12 & 26 & 14 \\
\hline EC II $\times$ HiTiP 88 & 140 & 292 & 6.1 & 3.8 & 4 & 5 & 24 & 28 \\
\hline EC $87 \times$ HiTiP 89 & 138 & 241 & $28.4 *$ & 7.2 & 26 & 7 & 28 & 6 \\
\hline EC-C6 $\times$ LRE 128 & 138 & 313 & 18.9 & $21.0 *$ & 1 & 22 & 9 & 15 \\
\hline EC $87 \times$ HiTiP 88 & 138 & 261 & 14.6 & -0.7 & 14 & 11 & 27 & 18 \\
\hline EC II $\times$ EC 87 & 137 & 273 & 6.4 & 6.7 & 9 & 1 & 34 & 9 \\
\hline EC $87 \times$ LRE 128 & 136 & 283 & $22.0 *$ & 7.9 & 7 & 26 & 14 & 7 \\
\hline EC-C6 $\times$ EC 87 & 136 & 261 & 8.9 & 4.7 & 15 & 16 & 30 & 19 \\
\hline EC-C6 $\times$ HiTiP 88 & 136 & 254 & 8.3 & -3.7 & 20 & 10 & 23 & 31 \\
\hline LSD0.05 & 25 & 56 & - & - & - & - & - & - \\
\hline
\end{tabular}

* Difference between midparent and population cross mean at the 0.05 and probability level.

** Difference between midparent and population cross mean at the 0.01 probability level.

$\dagger$ Ranks from 1-36, low numbers indicate high SY, high number of PP, late flowering, and high thousand grain weight. 

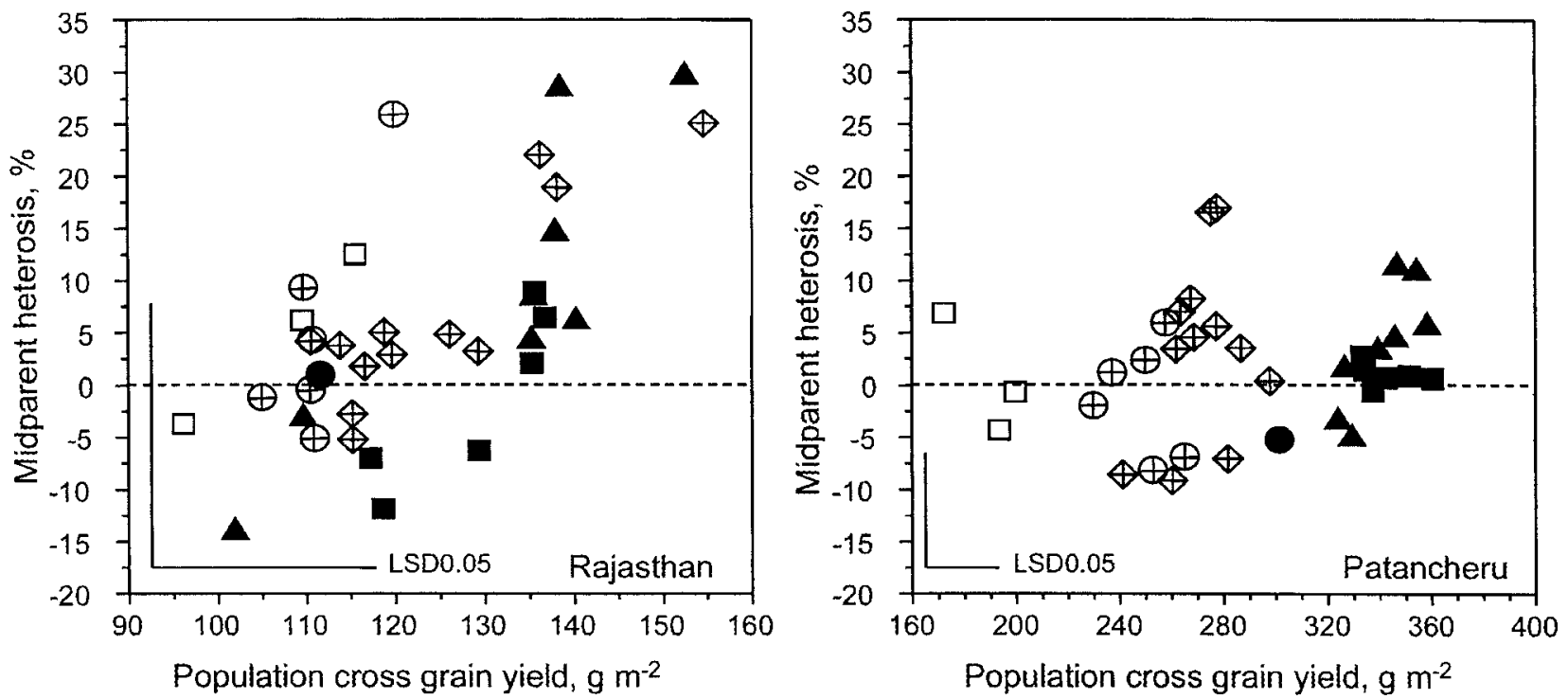

Crosses:

- Elite $x$ Elite

- Elite high-tillering $x$ Elite high-tillering

- Landrace $x$ Landrace

- Elite $\times$ Elite high-tillering

$\bullet \quad$ Elite $x$ Landrace

$\oplus \quad$ Elite high-tillering $\times$ Landrace

Fig. 1. Relationship between population cross grain yield and midparent heterosis averaged across the three Rajasthan environments (left) and the three Patancheru environments (right).

For SY, mean superiority of population crosses over their parents was significantly positive and higher than for GY (Table 1). The magnitude of differences, however, was also variable across environments, and significant only in four out of eight environments. The highest heterosis values were observed in the marginally drought stressed environment, Jodhpur (1992), and in the favorable environment of Patancheru (1992).

Average heterosis for TF was generally low and significant only in the Jodhpur (1992) and the Patancheru (1993) experiments. The number of PP showed significant negative heterosis in the lowest yielding environment, Jodhpur (1991), and significant positive heterosis in the highest yielding environment. Thousand-grain weight showed a mean superiority of population crosses over parents of $4.35 \%$, and significant heterosis was observed in all three groups of environments [Jodhpur (1991,1992), Hisar (1991), and Patancheru (1992)].

Gardner and Eberhart's Analysis II revealed, for all traits, highly significant variation for population and heterosis effects when computed across all environments (Table 5). Contributions of heterosis effects to the entry sum of squares were generally low, ranging from 5 to $12 \%$, except for SY, where the proportion of heterosis effects accounted for $44 \%$ of the entry sum of squares.

When the analyses of variance were computed separately for each of the three groups of environments,

Table 5. Mean squares and percentages of sum of squares for the variance of the genetic parameter from the Gardner and Eberhart analysis II of the nine parent populations and their 36 crosses for grain yield (GY), stover yield (SY), time to flowering (TF), and panicles per plant (PP) across eight environments (Env.), and for thousand-grain weight (TG) across seven environments.

\begin{tabular}{|c|c|c|c|c|c|c|c|c|c|c|c|c|}
\hline \multirow[b]{2}{*}{ Source } & \multirow[b]{2}{*}{ DF } & \multicolumn{2}{|c|}{ GY } & \multicolumn{2}{|c|}{ SY } & \multicolumn{2}{|c|}{$\mathbf{T F}$} & \multicolumn{2}{|c|}{$\mathbf{P P}$} & \multicolumn{3}{|c|}{ TG } \\
\hline & & MS & $\%$ SS & MS & $\% \mathrm{SS}$ & MS & $\% \mathrm{SS}$ & MS & $\% \mathrm{SS}$ & DF & MS & $\%$ SS \\
\hline Entries & 44 & $7882 * *$ & 100 & $6885^{* * *}$ & 100 & 28.07** & 100 & $\mathbf{4 . 5 0} * *$ & 100 & 44 & $7.84 * *$ & 100 \\
\hline Populations $\left(p_{i}\right)$ & 8 & $40170 * *$ & 93 & $21151 * *$ & 56 & $136.25 * *$ & 88 & $23.55 * *$ & 95 & 8 & $38.97 * *$ & 90 \\
\hline Heterosis $\left(h_{\mathrm{ij}}\right)$ & 36 & $\mathbf{7 0 8}^{* * *}$ & 7 & $3 \mathbf{7 1 5}^{* *}$ & 44 & $\mathbf{4 . 0 3}^{*} *$ & 12 & $0.27 * *$ & 5 & 36 & $0.92 * *$ & 10 \\
\hline Average (h) & 1 & 556 & $\mathbf{0}$ & $20846^{* * *}$ & 7 & 8.02* & 1 & 0.06 & $\mathbf{0}$ & 1 & $5.85 * *$ & 2 \\
\hline Population $\left(h_{i}\right)$ & 8 & $735^{*}$ & 2 & $3431 *$ & 9 & $11.99 * *$ & 8 & $\mathbf{0 . 2 8 *}$ & 1 & 8 & $1.27 * *$ & 3 \\
\hline Specific $\left(\mathrm{s}_{\mathrm{ij}}\right)$ & 27 & $705 * *$ & 5 & 3165 ** & 28 & $1.52 *$ & 3 & $0.27 * *$ & 4 & 27 & $0.64 * *$ & 5 \\
\hline Env. $\times$ Entries & 308 & $\mathbf{7 7 0}^{* *}$ & & $1472 * *$ & & $1.39 * *$ & & $0.17 * *$ & & 264 & $\mathbf{0 . 3 0} * *$ & \\
\hline Env. $\times p_{i}$ & 56 & $2976^{* * *}$ & & $2820 * *$ & & 3.41** & & $0.33 * *$ & & 48 & $1.02 * *$ & \\
\hline Env. $\times \mathbf{h}_{\mathrm{ij}}$ & 252 & $279 *$ & & $1172 *$ & & 0.94 & & $\mathbf{0 . 1 4} * *$ & & 216 & 0.14 & \\
\hline Env. $\times$ h & 7 & 215 & & 1158 & & 0.69 & & $0.26 * *$ & & 6 & 0.19 & \\
\hline Env. $\times \mathbf{h}_{\mathbf{i}}$ & 56 & 267 & & $1452 *$ & & 1.02 & & 0.11 & & 48 & 0.14 & \\
\hline Env. $\times \mathbf{s}_{\mathrm{ij}}$ & 189 & $285 *$ & & 1090 & & 0.93 & & $0.14 * *$ & & 162 & 0.14 & \\
\hline Error & & 233 & & 999 & & 0.82 & & 0.10 & & & 0.13 & \\
\hline DF error & & 1722 & & 1723 & & 1757 & & 1741 & & & 1411 & \\
\hline
\end{tabular}

* Significant at the 0.05 probability level.

** Significant at the 0.01 probability level. 
Table 6. Mean squares and percentages of sum of squares for the variance of the genetic parameter from the Gardner and Eberhart (1966) analysis II of the nine parent populations and their 36 crosses for grain and stover yield across the three Rajasthan, the two Hisar, and the three Patancheru environments (Env.).

\begin{tabular}{|c|c|c|c|c|c|c|c|c|c|c|c|c|c|c|c|}
\hline \multirow[b]{3}{*}{ Source } & \multicolumn{5}{|c|}{ Rajasthan } & \multicolumn{5}{|c|}{ Hisar } & \multicolumn{5}{|c|}{ Patancheru } \\
\hline & \multirow[b]{2}{*}{ DF } & \multicolumn{2}{|c|}{ Grain yield } & \multicolumn{2}{|c|}{ Stover yield } & \multirow[b]{2}{*}{ DF } & \multicolumn{2}{|c|}{ Grain yield } & \multicolumn{2}{|c|}{ Stover yield } & \multirow[b]{2}{*}{ DF } & \multicolumn{2}{|c|}{ Grain yield } & \multicolumn{2}{|c|}{ Stover yield } \\
\hline & & MS & $\% \mathrm{SS}$ & MS & $\% \mathrm{SS}$ & & MS & $\%$ SS & MS & $\%$ SS & & MS & $\% \mathrm{SS}$ & MS & $\%$ SS \\
\hline Entries & 44 & $645 * *$ & 100 & $2048 *$ & 100 & 44 & $1877 * *$ & 100 & 3525 & 100 & 44 & $9260 * *$ & 100 & $4849 * *$ & 100 \\
\hline Population $\left(p_{i}\right)$ & 8 & $1733 *$ & 49 & 5679 & 50 & 8 & $8341 * *$ & 81 & 7259 & 37 & 8 & $48607 * *$ & 95 & $15172 * *$ & 57 \\
\hline Heterosis $\left(\mathbf{h}_{\mathrm{ij}}\right)$ & 36 & $404 *$ & 51 & 1241 & 50 & 36 & 441 & 19 & 2695 & 63 & 36 & 516 ** & 5 & $2555 * *$ & 43 \\
\hline Average (h) & 1 & 696 & 2 & 2031 & 2 & 1 & 82 & 0 & 7748 & 5 & 1 & 381 & 0 & 14123 & 7 \\
\hline Population $\left(h_{i}\right)$ & 8 & 183 & 5 & 473 & 4 & 8 & 384 & 4 & $5835^{*}$ & 30 & 8 & $910 *$ & 2 & 2806 & 11 \\
\hline Specific $\left(s_{i j}\right)$ & 27 & $458 *$ & 44 & 1439 & 43 & 27 & 471 & 15 & 1577 & 27 & 27 & 405 & 3 & $2052 * *$ & 26 \\
\hline Env. $\times$ Entries & 88 & 277 & & $11^{*} * *$ & & 44 & 363 & & 2166 & & 88 & $285^{*}$ & & $1118 * *$ & \\
\hline Env. $\times$ p $_{i}$ & 16 & $542 * *$ & & $2809 * *$ & & 8 & 205 & & 3097 & & 16 & $518 * *$ & & $2033 * *$ & \\
\hline Env. $\times \mathbf{h}_{\mathrm{ij}}$ & 72 & 219 & & 821 & & 36 & 398 & & 1959 & & 72 & 233 & & 915 & \\
\hline Env. $\times$ h & 2 & 99 & & 489 & & 1 & 652 & & 1427 & & 2 & 27 & & 1324 & \\
\hline Env. $\times \mathbf{h}_{\mathbf{i}}$ & 16 & 181 & & 347 & & 8 & 289 & & 1610 & & 16 & 238 & & 1089 & \\
\hline Env. $\times s_{i j}$ & 54 & 234 & & 974* & & 27 & 421 & & 2082 & & 54 & 240 & & 848 & \\
\hline Error & & 240 & & 688 & & & 238 & & 1863 & & & 222 & & 733 & \\
\hline DF error & & 464 & & 472 & & & 461 & & 464 & & & 797 & & 787 & \\
\hline
\end{tabular}

* Significant at the 0.05 probability level.

** Significant at the 0.01 probability level.

GY showed significant or highly significant population effects (Table 6). Variation of heterosis effects for GY was also significant when combined across the Rajasthan environments and $51 \%$ of the entry sum of squares could be explained by heterosis effects. The subdivision of heterosis into average, population, and specific heterosis showed that most of this variation could be attributed to specific heterosis effects. A different pattern was observed in the analyses of GY across the Patancheru environments. Although heterosis was highly significant in Patancheru, it accounted only for $5 \%$ of the entry sum of squares and the variation among entries was mainly caused by population effects. The variation of heterosis was nonsignificant combined across the two Hisar environments.

The SY population and heterosis effects were nonsignificant in the Rajasthan and Hisar groups of environments, but highly significant in Patancheru. As in the case of GY, specific heterosis was more important than population heterosis at Patancheru.

\section{Relationships among Traits}

The number of PP was negatively correlated with GY, whereas late flowering and high TG were positively associated with GY (Table 7). These correlations were

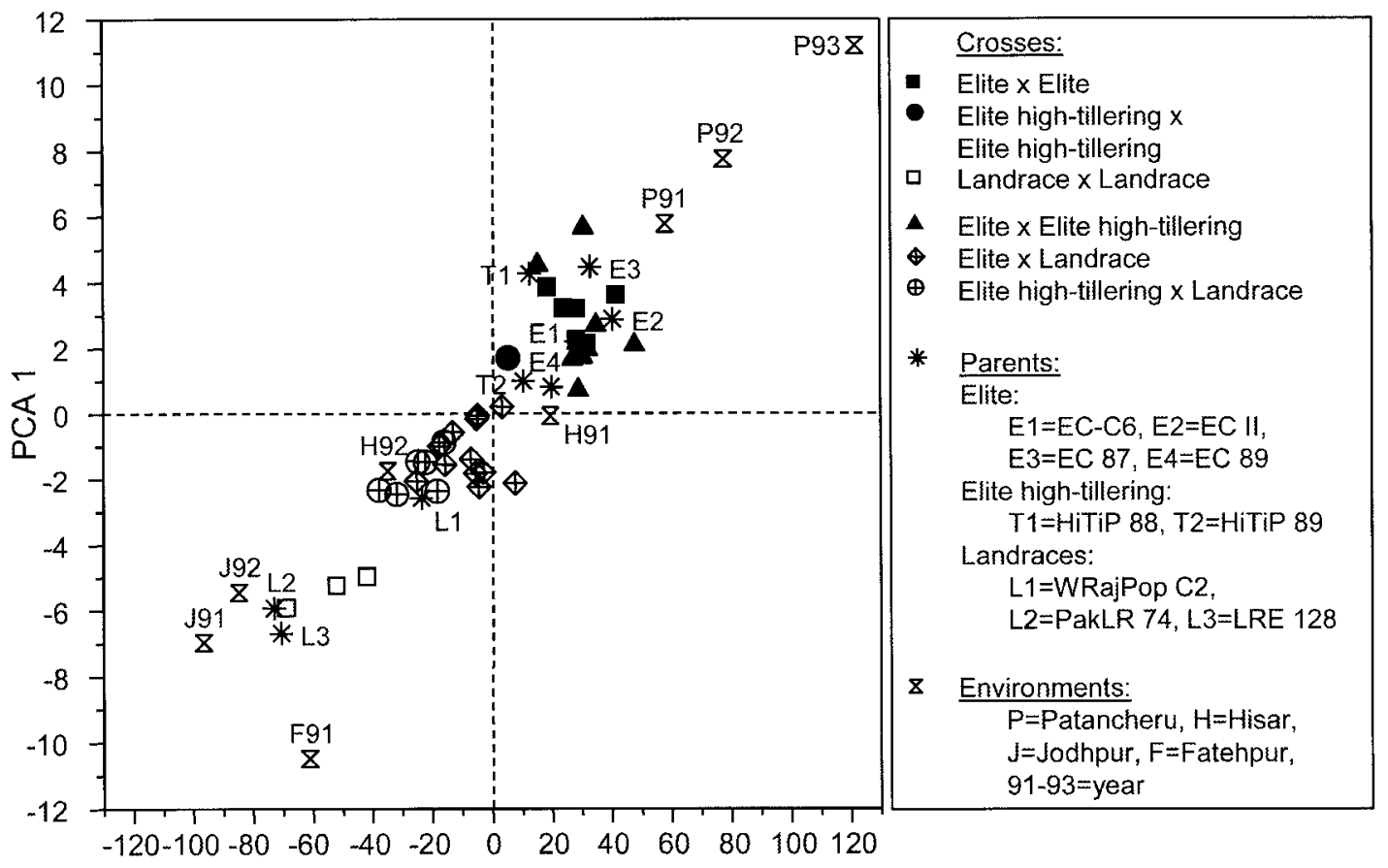

Additive effect for grain yield

Fig. 2. Additive effects (deviation of individual mean of population or environment from overall mean) and principal component axis 1 (PCA 1) from the additive main effects and multiplicative interaction analysis for grain yield. 
Table 7. Coefficients of phenotypic correlation between grain yield (GY) and stover yield (SY), time to flowering (TF), panicles per plant (PP), and thousand-grain weight (TG) combined across the 36 cross populations and across the three Rasjasthan (RAS), the two Hisar (HIS), and the three Patancheru (PAT) environments.

\begin{tabular}{|c|c|c|c|c|c|c|}
\hline & \multicolumn{3}{|c|}{ GY } & \multicolumn{3}{|c|}{ SY } \\
\hline & RAS & HIS & PAT & RAS & HIS & PAT \\
\hline SY & $0.51^{* * *}$ & -0.14 & 0.21 & - & - & - \\
\hline TF & 0.33* & 0.10 & $0.58^{* *} *$ & 0.24 & 0.25 & $0.72 *$ \\
\hline PP & $-0.48 * *$ & $-0.65 * *$ & $-0.81 * *$ & 0.04 & 0.00 & $-\mathbf{0 . 0 7}$ \\
\hline TG & $0.49 * *$ & n.a. $\dagger$ & $0.75^{*} *$ & 0.13 & 0.12 & 0.08 \\
\hline
\end{tabular}

* Significant at the 0.05 probability level.

** Significant at the 0.01 probability level.

+ n.a., not assessed.

strongest in the highest yielding Patancheru environments and only moderate to nonsignificant in the more stress-prone environments. Stover yield showed significant correlations only with GY in Rajasthan and TF in Patancheru. The magnitude and sign of the correlation among traits of crosses and traits of parents were generally comparable, although especially in the Patancheru environments, the correlations between traits of crosses were smaller compared with associations between traits of parent populations (data not shown).

\section{DISCUSSION}

\section{Heterosis in Contrasting Environments}

The presence of heterosis for different traits of pearl millet has been reported in numerous studies. Virk (1988) gave a detailed review. Most estimates were obtained using diallel and line $\times$ tester designs with inbred parents and were, therefore, not comparable to the results with noninbred materials. Ouendeba et al. (1993) investigated heterosis and combining ability among five African pearl millet landraces. In contrast to the present study, estimates of better-parent heterosis for GY were positive in all crosses and ranged from 25 to $80 \%$. Ali et al. (2001) evaluated 11 medium to late maturity pearl millet populations and their diallel crosses in five environments in India. Both population and heterosis effects for GY were significant and heterosis explained $25 \%$ of the entry sum of squares. The subdivision of the heterosis sum of squares revealed only significant average heterosis, whereas population and specific heterosis effects were nonsignificant.

In the present study, average level of heterosis across environments was low, mainly because positive and negative heterosis values balanced each other out. The parent populations differed widely in their plant architecture and origin. Therefore, insufficient genetic diversity could not explain the low average heterosis and the occurrence of negative heterosis, especially in the wide crosses between landraces and elite materials. The elite populations differed in their content of African and Indian germplasm, but there was no obvious heterotic pattern related to the origin of the elite populations. The landrace parents originated from the dry areas of northwestern India and Pakistan, and the elite parents were developed in the Patancheru environment. There- fore, adaptation to different local conditions could be one reason for the comparatively low heterosis values, and could be explained through coadapted genes, at many loci, interacting in an epistatic manner. When such populations are crossed, the $F_{1} \mathrm{~s}$ are adapted to neither of the different environments (Moll et al., 1965; Geiger, 1988; Falconer and MacKay, 1996). The present study was not designed to estimate such epistatic effects.

For GY, expression of heterosis in this set of materials depended on the environmental conditions, and more positive heterosis values occurred under drought stress in the Rajasthan environments. Haussmann et al. (1998) obtained similar results with sorghum lines and hybrids in Kenya. Pethani and Dave (1992) reported that levels of heterosis for pearl millet in different environments changed. Bidinger et al. (1994) and Yadav et al. (2000) evaluated topcross hybrids between elite male-sterile lines and landraces as pollinators in different environmental zones of Rajasthan and under terminal drought conditions in Patancheru. Heterosis was calculated as the superiority of the hybrid over its landrace pollinator. Average heterosis for most of the traits tended to be greater under drought stress conditions than in the environments with only mild stress. For GY, results depended on the male-sterile parent. Crosses with one malesterile line showed greater heterosis under drought stress, whereas hybrid superiority of the crosses with the other line was greater under more favorable conditions. Highest estimates for heterosis were, however, obtained under conditions of terminal drought. This could be partly caused by the lack of adaptation of landraces to the Patancheru environment.

The population crosses, especially those involving landrace parents, expressed a relatively high number of panicles with unusually poor seed set (data not shown). Subsequent observations of some of the same populations in test crosses with male-sterile lines indicated that this poor seed was caused by chromosome translocations segregating in these populations. This could partially explain the low levels of heterosis, and its high level of specificity, but not the variability across different groups of environments.

Midparent heterosis for SY was on average higher than for GY and significant across environments, which is in contrast to the study of Yadav et al. (2000). It was also variable across environments but followed a different pattern than heterosis for GY. Heterosis tended to be higher than for GY in all favorable environments, including Jodhpur in 1992, the year with the higher seasonal rainfall within the Rajasthan environments. The Gardner and Eberhart Analysis II across all environments showed a much higher percentage of sum of squares explained through heterotic effects for SY (44\%) than for GY (7\%). All three components of heterosis were significant, with the largest contribution of specific effects. When individual analyses were performed for the different groups of environments, however, heterotic effects were only significant in Patancheru, and specific effects dominated. Burton (1968) tested 106 pearl millet $F_{1}$ hybrids from inbred lines in three years for their total annual forage yield (three to four 
cuttings per year). In contrast to our results, the hybrids outyielded their inbred parents by a greater margin in a year with strong environmental stress conditions (73\%) than in a favorable growing season (53\%).

Drought escape through early flowering is advantageous in growing seasons with terminal drought stress. On the other hand, later anthesis can be beneficial in escaping early season drought stress (Bidinger et al., 1987; van Oosterom et al., 1996). Heterosis for earliness is common in pearl millet and has also been reported by Bidinger et al. (1994) and Yadav et al. (2000). In a study with topcross hybrids on extremely early malesterile lines, the greatest yield superiority of hybrids over landrace parents was observed in a terminal stress environment where the hybrids escaped drought stress via earlier flowering (Yadav et al., 2000). In the present study, population crosses flowered on average $0.4 \mathrm{~d}$ later than their parents, resulting in a slightly positive heterosis for $\mathrm{TF}$, and possibly a yield advantage at the three Rajasthan locations, where early season drought occurred.

\section{Usefulness of Population Crosses}

The aims of pearl millet breeding programs for aridzone environments are good adaptation to variable drought stress to minimize the risk of crop failure in unfavorable years, high yield potential for both grain and SY, and high food and fodder quality. The landraces showed good adaptation to the local environments of Rajasthan. Their plant type differed considerably from that of elite breeding populations, in being high-tillering, small-seeded, and early-flowering. The early flowering would seem to maximize grain fill by escaping terminal drought stress. Unfortunately, during the $3 \mathrm{yr}$ of this study, only early season drought stress was observed. The high tillering capacity enables the formation of new tillers in response to continuing or intermittent rainfall. These are characteristics that farmers associate with good adaptation to severe stress conditions (van Oosterom et al., 1996; vom Brocke et al., 2000).

Many of the population crosses did combine productivity traits of the elite populations and the adaptive traits of the landraces. Among the 10 superior crosses in Rajasthan, three involved a landrace parent. These three crosses showed not only good grain and stover productivity but also were the earliest flowering and had the highest number of PP among the 10 highestyielding crosses. Eight of the 10 highest-yielding crosses in Rajasthan were combinations of high-tillering materials (landraces and elite high-tillering populations) with elite populations. In contrast, at Patancheru, only five such populations were among the top 10 and none of them was derived from a cross with a landrace. In Rajasthan, however, only two of the population crosses derived from high-tillering materials expressed an aboveaverage number of PP $($ EC-C6 $\times$ LRE 128 and EC $87 \times$ LRE 128).

Livestock are a very important part of the agricultural production systems in arid-zone environments. Therefore, in addition to using pearl millet grain as human food, SY and quality are of great economic importance for farmers. As mentioned before, heterosis for SY was significant and important when analyzed across all environments. A moderate positive correlation between stover and GY occurred in Rajasthan, and among the 10 highest yielding population crosses were five populations with SY ranks among the top 10. It is interesting that the three highest grain yielding landrace crosses were also superior in SY. It should, therefore, be possible to combine high potential for grain and SY in one population. Two of these landrace crosses were also higher tillering than the elite populations, which is an indicator of stover quality often used by farmers in Rajasthan (Christinck et al., 2000).

\section{Implications for Pearl Millet Breeding Programs in Arid-Zone Environments}

Choosing the right germplasm is an important prerequisite for a successful breeding program. Basic materials for breeding should have a high mean performance and high genetic variability to maximize gains from selection (Schnell, 1983). High genetic variability can be expected in population crosses showing high levels of heterosis. The three population crosses involving landrace parents (EC $89 \times$ WRajPop C2, EC-C6 × LRE 128, and EC $87 \times$ LRE 128) did express high means and high levels of heterosis for GY. These three populations were also superior in SY and two of them had above average tillering potential. Earliness of the three populations should be improved because the population crosses of LRE 128 were $\approx 3 \mathrm{~d}$ later compared with their landrace parent (data not shown). Therefore, these crosses could be used to widen the germplasm base and to combine the high yield potential of elite materials with the good adaptation of the landraces.

In another study, subsequent recurrent selection efforts in populations based on the highest-yielding crosses between landrace and elite parents did show the expected gains in yield stability (Yadav and WeltzienRattunde, 1998). The improved populations outyielded landrace cultivars in early and late season stress years, as well as in favorable years. Selection in landrace populations alone did not result in productivity gains across a broad range of more favorable conditions.

Our results indicate the great value of local landraces as genetic resources for pearl millet breeding programs targeting arid environments. The suitability of source populations, however, varied depending on the specific interaction among these source populations and on their reaction to the environment. In practice, information about the usefulness of such resources regarding quantitative characteristics, such as adaptation, yield potential, or heterotic pattern is lacking for most cases. To improve the usefulness of such genetic resources, detailed evaluations of landraces collected from farmers' fields would be highly desirable and should be performed in the target environments.

\section{Implications for Farmer Participatory Breeding Programs}

Farmers in Rajasthan have developed strategies to improve productivity and to increase diversity within 
their landraces through introgression of modern cultivars (Dhamotharan et al., 1997; Weltzien R. et al., 1998; vom Brocke et al., 2000, 2002). Farmers expect that the mixed and outcrossed populations increase the adaptive range of their seed stocks by maintaining specific landrace plant types, well adapted to stress, and adding elite plant types that respond better to improved growing conditions. Population crosses between elite and landrace materials showing high heterosis are one way to broaden genetic variability in farmer-maintained landraces. Our study supports farmers' experiences. This study also showed, however, that not all combinations between landraces and elite materials had the same benefits. While many of the elite $\times$ landrace crosses showed GY considerably above the best landrace parent, only three crosses had a high GY performance and a high level of heterosis. Thus, only these crosses offer good chances for increased gains from selection (also by farmers). To support the farmers' breeding efforts, it could be helpful to test their landraces in combination with a range of improved materials. One could identify those elite materials offering the greatest benefits to farmers, who are interested in mixing, crossing, and selecting in diversified landrace populations.

The analysis of the environment $x$ entry interaction effects also showed clearly that only the landrace parents and the landrace $\times$ landrace crosses clustered near the stress environments. All the elite $\times$ landrace crosses, as well as the improved landrace population (WRajPop $\mathrm{C} 2$ ) clustered with the intermediate Hisar environments. Thus, there seems to be a clear loss of adaptation associated with these type of wide crosses. This confirms reports from poor farmers who have to grow pearl millet under the most severe stress conditions. They observed a loss of adaptation of such crossed materials they received from better-off farmers (Dhamotharan et al., 1997, Christinck, 2002). Vom Brocke et al. (2002) confirmed these observations by comparing farmer-managed seed stocks in field experiments. It remains to be explored if selection within these population crosses in the target environment can recover some of this adaptation to stress, while maintaining responsiveness to good growing conditions. Routine evaluations of such populations in on-station trials of selection done on the research station indicated that this is possible (Yadav and Weltzien R., 1998). Thus, population crosses do offer opportunities for exploiting heterosis through population breeding, in conjunction with a suitable selection strategy to meet farmers' needs for adaptation, responsiveness, and quality traits.

\section{ACKNOWLEDGMENTS}

We thank the following for their contribution to this study: Drs. O.P. Yadav, V.K. Manga, T.R. Sharma, and R.L. Kapoor for their support and interest in conducting these trials at the various research stations in northern India; Mr. Basheer Ahmed, Mr. Ram Reddy, Mr. Chandra, and Mr. Mohan Rao for the excellent management of these trials under severe stress conditions, for taking observations, and the initial data entry; Dr. S. Chandhra and Mr. Prabakhar for helping with the GENSTAT software; Prof. Dr. H.H. Geiger for supporting
Dr. T. Presterl's work at ICRISAT; and Dr. K. vom Brocke and Dr. F. Rattunde for their helpful comments and suggestions on the manuscript.

\section{REFERENCES}

Ali, A.M., C.T. Hash, A.E.S. Ibrahim, and A.G.B. Raj. 2001. Population diallel of elite medium- and long-duration pearl millet composites: I. Populations and their $F_{1}$ crosses. Crop Sci. 41:705-711.

Bidinger, F.R., V. Mahalakshmi, and G.D.P. Rao. 1987. Assessment of drought resistance in pearl millet (Pennisetum americanum (L.) Leeke). Aust. J. Agric. Res. 38:37-59.

Bidinger, F.R., E. Weltzien R., V. Mahalakshmi, S.D. Singh, and K.P. Rao. 1994. Evaluation of landrace topcross hybrids of pearl millet for arid zone environments. Euphytica 76:215-226.

Burton, G.W. 1968. Heterosis and heterozygosis in pearl millet forage production. Crop Sci. 8:229-230.

Christinck, A., K. vom Brocke, and E. Weltzien. 2000. What is a variety: Investigating farmers' concepts as a base for participatory plant breeding in Rajasthan, India. In International agricultural research. A contribution to crisis prevention. Conf. Tropical Agriculture and Forestry, Stuttgart, Germany. 11-12 October 2000 Univ. of Hohenheim, Tropenzentrum, Stuttgart, Germany. Available online at http://www.wiz.uni-kassel.de/tropentag/proceedings/ 2000/start.pdf (verified 27 Aug. 2002).

Christinck, A. 2002. "This seed is like ourselves"-A case study from Rajasthan, India, on the social aspects of biodiversity and farmers management of pearl millet seed. Margraf Verlag, Weikersheim, Germany.

Cochran, W.G., and G.M. Cox. 1957. Experimental designs. 2nd ed. John Wiley and Sons, London.

Crossa, J., H.G. Gauch, Jr., and R.W. Zobel. 1990. Additive main effects and multiplicative interaction analysis of two international maize cultivar trials. Crop Sci. 30:493-500.

Dhamotharan, M., E. Weltzien, M.L. Whitaker, H.F. Rattunde, M.M. Anders, L.C. Tiagi, V.K. Manga, and K.L. Vyas. 1997. Seed management strategies of farmers in western Rajasthan in their social and environmental contexts: Results from a workshop using new communication techniques for a dialogue between farmers and scientists, 5-8 February 1996, Digadi village, Jodhpur district, Rajasthan, India. Integrated Systems Project Progress Rep. No. 9 ICRISAT, Patancheru, India.

Falconer, D.S., and T.F.C. Mackay. 1996. Introduction to quantitative genetics. 4th ed. Longman Scientific and Technical, New York.

Gardner, C.O., and S.A. Eberhart. 1966. Analysis and interpretation of the variety cross diallel and related populations. Biometrics 22 : 439-452.

Geiger, H.H. 1988. Epistasis and heterosis. p. 395-399. In B.S. Weir, E.J. Eisen, M.M. Goodman, and G. Namkoong (ed.) Proc. 2nd Int. Conf. on Quantitative Genetics. Sinauer Assoc., Sunderland, MA.

Haussmann, B.I.G., A.B. Obilana, A. Blum, P.O. Ayiecho, W. Schipprack, and H.H. Geiger. 1998. Hybrid performance of sorghum and its relationship to morphological and physiological traits under variable drought stress in Kenya. Plant Breed. 117:223-229.

Kelley, T.G., P. Partasarathy Rao, E. Weltzien R., and M.L. Purohit. 1996. Adoption of improved cultivars of pearl millet in an arid environment: Straw yield and quality considerations in western Rajasthan. Expl. Agric. 32:161-171.

Link, W., B. Schill, and E. von Kittlitz. 1996. Breeding for wide adaptation in faba bean. Euphytica 92:185-190.

Moll, R.H., J.H. Lonquist, J.V. Fortuno, and E.C. Johnson. 1965. The relationship between heterosis and genetic divergence in maize. Genetics 52:139-144.

Ouendeba, B., G. Ejeta, W.E. Nyquist, W.W. Hanna, and A. Kumar. 1993. Heterosis and combining ability among African pearl millet. Crop Sci. 33:735-739.

Pethani, K.V., and H.R. Dave. 1992. Heterosis for grain yield in pearl millet (Pennisetum typhoides (B.) S. and H.). Indian J. Gent. Plant Breed. 52:45-59.

Schnell, F.W. 1983. Probleme der Elternwahl-Ein Überblick (in German). p. 1-11. In Arbeitstagung der Arbeitsgemeinschaft der Saatzuchtleiter. 22-24. Nov. 1983. Verlag und Druck der Bundesanstalt für alpenländische Landwirtschaft, Gumpenstein, Austria.

Van Oosterom, E.J., M.L. Whitaker, and E. Weltzien R. 1996. Inte- 
grating genotype-by-environment analysis, characterisation of drought patterns, and village surveys to identify adaptive plant traits for pearl millet in Rajasthan. p. 383-402. In M. Cooper and G.L. Hammer (ed.) Plant adaptation and crop improvement. CAB International, Oxon, UK; IRRI, Manila, The Philippines; and ICRISAT, Patancheru, India.

Virk, D.S. 1988. Biometrical analysis in pearl millet—A review. Crop Improv. 15:1-29.

vom Brocke, K., A. Christinck, and E. Weltzien R. 2000. Farmers seed management strategies and their effects on pearl millet populations-Examples from Rajasthan, India. In Knowledge and Partnership. Challenges and Perspectives for Research and Education at the Turn of the Millennium. Conf. Tropical Agriculture and Forestry, Berlin, Germany. 14-15 Oct. 1999. CD-ROM computer file available at http://www.wiz.uni-kassel.de/tropentag/program/ proceedings.html (verified 1 Nov. 2002). Univ. of Berlin, Berlin.

vom Brocke, K., T. Presterl, A. Christinck, E. Weltzien R., and H.H. Geiger. 2002. Farmers' seed management practices open up new base populations for pearl millet breeding in a semi-arid zone of India. Plant Breed. 121:36-42.
Weltzien R., E., and M.S. Bhatti. 1991. Pearl millet collecting in central Pakistan. Plant Genet. Resour. Newsl. 85:28-29.

Weltzien R., E., and S.B. King. 1995. Recurrent selection for downy mildew in pearl millet. Plant Breed. 114:308-312.

Weltzien R., E., M.L. Whitaker, H.F.W. Rattunde, M. Dhamotharan, and M.M. Anders. 1998. Participatory approaches in pearl millet breeding. p. 143-170. In J.R. Witcombe et al. (ed.) Seeds of choice: Making the most of new varieties for small farmers. Oxford and IBH Publishing Co., Delhi, India.

Weltzien R., E. 2000. Supporting farmers' genetic resources management. Experiences with pearl millet in India. p. 189-193. In C Almekinders and W. de Boef (ed.) Encouraging diversity. The conservation and development of plant genetic resources. Intermediate Technology Publ., London, UK.

Yadav, O.P. and E. Weltzien R. 1998. New pearl millet populations for Rajasthan, India. Integrated Systems Rep. Series no. 10. Int Crops Res. Inst. for the Semi-Arid Tropics, Patancheru, India.

Yadav, O.P., E. Weltzien-Rattunde, F.R. Bidinger, and V. Mahalakshmi. 2000. Heterosis in landrace-based topcross hybrids of pearl millet across arid environments. Euphytica 112:285-295. 